\title{
Analysis of environmental impacts of renewable energy on the Moroccan electricity sector: A System Dynamics approach
}

\author{
M. CHENTOUF ${ }^{\mathrm{a},{ }^{*}, M}$. ALLOUCH ${ }^{\mathrm{a}}$ \\ ${ }^{\text {a }}$ Laboratoire des Matériaux et Valorisation des Ressources (LMVR), Faculté des Sciences et \\ Techniques de Tanger, Ancienne Route de l'Aéroport, Km 10, Ziaten. BP 416 - Tangier, Morocco.
}

\begin{abstract}
Producing electricity at an affordable price while taking into account environmental concerns has become a major challenge in Morocco. Moreover, the technical and financial issues related to renewable electricity plants are still hindering their efficient integration in the country. In fact, the energy sector (both electricity and heat) accounted for more than half of all Greenhouse Gases (GHG) emissions in the kingdom due to the major reliance on fossil fuels for answering the growing local demand. The key strategies to alleviate this critical situation include the integration of more renewable energies in the total energy mix and the enhancement of energy efficiency measures in different sectors. This paper strives to (1) evaluate the potential of carbon dioxide mitigation in Moroccan electricity sector following the actual and projected strategies and (2) highlight the policy schemes to be taken in order to achieve the ambitious carbon dioxide mitigation targets in the mid-term. A system dynamics model was built in order to simulate different scenarios of carbon dioxide mitigation policies up to 2030. The results shows that the achievement of renewable energies projects by 2030 could save 228.143 $\mathrm{MtCO} 2$ between 2020 and 2030 and an additional $18.127 \mathrm{MtCO} 2$ could be avoided in the same period by enhancing energy efficiency measures.
\end{abstract}

Keywords: Morocco, Renewable Energy, Energy Efficiency, GHG emissions, System Dynamics.

\footnotetext{
* Corresponding author: mohammedchentouf2@gmail.com
} 


\section{Introduction}

Global warming and climate change are mainly attributed to the presence of a large amount of carbon dioxide $\left(\mathrm{CO}_{2}\right)$ in the atmosphere [1]. In fact, this heat-trapping gas is the major contributor to climate change among all human-influenced climate drivers [2]. This can be associated with its abundance in the atmosphere compared to other heat-trapping gases [3] and its large accumulation [4] due to its long life $\left(20 \%\right.$ of $\mathrm{CO}_{2}$ in the atmosphere can still exist up to 800 years from the time of the emission [1]). Almost $76.7 \%$ of Greenhouse Gas (GHG) emissions are $\mathrm{CO}_{2}$-based and fossil fuels on their own contribute to more than $73 \%$ of these emissions (of which $43 \%$ from coal, $36 \%$ from oil and $20 \%$ from natural gas [5]).

According to the IEA [6], the power sector (electricity and heat) uses $41 \%$ of global fossil fuels followed by the transportation sector $22 \%$ and the industrial sector $20 \%$. The remaining share is consumed in other sectors like agriculture and fishery.

The large share of fossil fuels in the power industry will most likely contribute to more adverse effects on the Earth's climate if no efficient measures were taken to limit its impacts. Hence, the further deployment of Renewable Energy (RE) technologies and Combined Heat and Power (CHP) plants seems to be an ideal solution for decarbonising this sector [7]. Moreover, the enhancement of energy measures is capable of avoiding the use of a considerable amount of these hydrocarbons and thus avoiding the resulted $\mathrm{CO}_{2}$ emissions.

The aim of this work is to (1) evaluate the potential of carbon dioxide mitigation in Moroccan electricity sector following the current and projected strategies, and to (2) the policy schemes to be taken in order to achieve the carbon dioxide mitigation targets in the mid-term.

The layout of this paper is as follows: Section 2 provides a background analysis of the energy sector in Morocco. Materials and methods for conducting this research work are provided in section 3 , followed by a detailed discussion of the results in section 4 . Finally, a conclusion of this work is given in section 5 .

\section{Background analysis}

\subsection{The energy situation in Morocco}

Morocco is a north-African country (only $14 \mathrm{~km}$ from Europe) with an area of 710,850 km2 and a coastline of $3500 \mathrm{~km}$ (shared between the Atlantic Ocean and the Mediterranean Sea). According to the population census of 2014 [8], Morocco's population is estimated at 33.8 million (an increase by $13.42 \%$ compared to 2014) with a density of 70.92 inhabitants $/ \mathrm{km} 2$. The kingdom of Morocco is considered as the largest fossil fuel importer in North-Africa [9] due to financial and economic barriers for developing local energy production facilities (e.g. oil shale) and the cheaper cost of energy imports compared to the total cost of exploring and investing in the local energy potential.

Electricity consumption per capita is the fastest growing sector among different energy sectors in Morocco (an increase by almost $100 \%$ between 1985 (0.08 toe/capita) and 2005 ( 0.16 toe/capita) $)$ and an additional 0.07 toe/capita has been recorded in 2015.This can be attributed to the implementation of the national programme for global rural electrification (PERG) in 1995, which enabled the connection of 12 million people to the national grid reaching an electrification rate of more than $99 \%$ in 2015 compared to only $18 \%$ in 1995 [11]. As a result of economic expansion and population growth, electricity demand is expected to continue its growth to reach $52 \mathrm{TWh}$ in 2020 (compared to $24 \mathrm{TWh}$ in 2008) and $95 \mathrm{TWh}$ in 2030 [12]. 
Table 1 shows some key indicators of the energy sector in Morocco over the period 2000 2014 [13]. Total Primary Energy Supply (TPES) has increased by almost $72.23 \%$ during these 15 years. Consequently, electricity consumption has doubled during the same period reaching 30.93 TWh in 2014 compared to 14.11 TWh in 2000 (an increase by 119\%) and resulting in an increase of carbon dioxide emissions by $0.55 \mathrm{tCO} 2 /$ capita up to 2014 .

Although carbon intensity is still fluctuating between $2.62 \mathrm{tCO} 2 /$ toe and $2.80 \mathrm{tCO} 2 /$ toe, the annual emissions of carbon dioxide have increased by $79.8 \%$ between 2000 and 2014 . This carbon footprint reflects the magnitude of intensive $\mathrm{CO} 2$ emitting sectors (mainly electricity and transportation) in Morocco, and the high reliance on fossil fuels for ensuring local energy needs. Almost two thirds of carbon dioxide emissions are generated from electricity and transportation activities. The industrial sector generates $15 \%$ of these emissions followed by the commercial sector (including agriculture and fishery) with $12 \%$ of carbon emissions.

\begin{tabular}{|c|c|c|c|c|c|c|c|c|c|c|c|c|c|c|c|}
\hline Indicators & 2000 & 2001 & 2002 & 2003 & 2004 & 2005 & 2006 & 2007 & 2008 & 2009 & 2010 & 2011 & 2012 & 2013 & 2014 \\
\hline $\begin{array}{l}\text { TPES } \\
\text { (Mtoe) }\end{array}$ & 11.02 & 11.68 & 11.87 & 11.82 & 14.02 & 14.84 & 15.10 & 15.57 & 16.17 & 16.28 & 17.08 & 18.40 & 18.66 & 18.74 & 18.98 \\
\hline $\begin{array}{l}\text { Electricity } \\
\text { Consumption } \\
\text { (TWh) }\end{array}$ & 14.11 & 15.29 & 15.79 & 17.32 & 18.44 & 19.32 & 21.20 & 22.35 & 23.13 & 23.81 & 25.10 & 27.07 & 29.15 & 29.72 & 30.93 \\
\hline $\begin{array}{l}\mathrm{CO}_{2} \text { emissions } \\
\left(\mathrm{Mt} \text { of } \mathrm{CO}_{2}\right)\end{array}$ & 29.54 & 32.19 & 33.33 & 33.06 & 36.29 & 38.89 & 40.18 & 40.96 & 42.75 & 42.72 & 45.95 & 50.26 & 51.75 & 50.47 & 53.11 \\
\hline $\begin{array}{l}\mathrm{CO}_{2} / \mathrm{TPES} \\
\left(\mathrm{tCO}_{2} / \text { toe }\right)\end{array}$ & 2.68 & 2.76 & 2.81 & 2.80 & 2.59 & 2.62 & 2.66 & 2.63 & 2.64 & 2.62 & 2.69 & 2.73 & 2.77 & 2.69 & 2.80 \\
\hline $\begin{array}{l}\mathrm{CO}_{2} / \text { population } \\
\text { (tCO } / \text { capita) }\end{array}$ & 1.02 & 1.10 & 1.13 & 1.11 & 1.21 & 1.28 & 1.31 & 1.32 & 1.36 & 1.35 & 1.43 & 1.55 & 1.57 & 1.51 & 1.57 \\
\hline
\end{tabular}

Table 1. Main indicators of the energy sector in Morocco between 2000 and 2014

\section{(Based on IEA data,www.iea.org/statistics, Licence: www.iea.org/t\&c; as modified by M.Chentouf and M.Allouch.)}

According to the IEA, $72.60 \%$ of $\mathrm{CO} 2$ emissions come from oil followed by $22.70 \%$ from coal and only $4.80 \%$ from natural gas. In fact, oil products accounted for $62 \%$ of TPES in 2014, while coal accounted for $21.26 \%$ and natural gas had a share of $5.3 \%$. It must be highlighted that the country imports over $95 \%$ of fossil fuels from abroad ranging from $100 \%$ of coal and $99.99 \%$ of oil to $85 \%$ of natural gas.

\subsection{The national response to climate change}

The country has been striving during the last few decades to limit the negative impacts of climate change on its vital economic sectors (e.g., agriculture, fishery and forestry). In fact, Morocco is increasingly vulnerable to climate change with an average warming estimated at $1{ }^{\circ} \mathrm{C}$ and rainfall variability between $3 \%$ and $30 \%$ [14]. Periods of droughts, floods and heat waves are expected to have adverse impacts in the upcoming years on water resources, agriculture and fishery products.

Several studies have been conducted in order to measure the impacts of climate change in Morocco including the work of Tramblay et al., [15] regarding the effects of climate change on extreme precipitation, the work of Simmonneaux et al., [16] on land use and climate 
change effects on soil erosion, and the work of Seif-Ennasr et al., [17] concerning climate change and adaptive water management measures in Morocco. The Moroccan endeavors to limit the impact of this global phenomenon dated back to 1992 when the country signed the United Nations Framework Convention on Climate Change (UNFCCC). In 1994, a national inventory on GHGs was achieved [18] and a National Committee for Climate Change (NCCC) was founded after the kingdom hosted the Conference of the Parties COP7 in 2001 in Marrakech. The third national communication submitted by the NCCC in 2015 includes 49 measures for mitigating GHG emissions to reach an average mitigation potential of 81.9 million tCO2 by 2040 [19].

Within this context, the National Energy Strategy (NES) adapted in 2009 stands as a key project among others for combating climate change in Morocco. The aim of the NES is to diversify the energy mix by introducing more renewable energies and supporting foreign investments in the sector [20]. Furthermore, the enhancement of energy efficiency measures is regarded as a promising tool for achieving the national mitigation targets of GHG emissions. Renewable energies will account of $42 \%$ of total installed capacity for electricity production ( $6 \mathrm{GW}$ shared evenly between solar, wind and hydropower) by 2020 compared to $33 \%$ in 2015 . An additional $10 \%$ of installed capacity is expected by 2030 . Actually, Morocco is blessed with favorable conditions for developing renewable energy projects. The exploitable potential of wind energy is estimated at 25,000 MW with an Average Wind Speed (AWS) ranging from $7.5 \mathrm{~m} / \mathrm{s}$ to $11 \mathrm{~m} / \mathrm{s}$ at $40 \mathrm{~m}$ [11]. The achievement of the Moroccan Integrated Programme of Wind Energy (MIPWE) will result in avoiding the emission of 5.6 MtCO2/year and generating an annual 6,600 GWh of electricity. Solar energy is also regarded as a vital source for ensuring the growing energy demand in the country. In fact, Morocco has an abundance of solar resources in several sites with more than 3000 hours of sunshine per year and $5 \mathrm{kWh} / \mathrm{m} 2 /$ year in terms of received energy. The average Direct Normal Irradiation (DNI) is estimated at $2300 \mathrm{kWh} / \mathrm{m} 2 /$ year being $30 \%$ higher than the best sites in Europe [21]. The technical potential of solar energy in Morocco is estimated at 10,829 MW and the fulfillment of the Moroccan Solar Plan will result in avoiding the emission of $3.7 \mathrm{MtCO} /$ year and generating an annual 4,500 $\mathrm{GWh}$ of electricity. Morocco has been using hydropower for generating electricity since 1929 and the potential of hydroelectric power is estimated at 3,800 MW. The NES defined the target of adding $580 \mathrm{MW}$ of hydroelectric capacity to reach $2 \mathrm{GW}$ of total installed capacity by 2020. This new capacity will be dedicated mainly to hydroelectric projects in Waste Water Treatment Plants (WWTPs) and micro-hydropower stations. The potential of biomass in Morocco is estimated at $950 \mathrm{MW}$ (issued mainly from agriculture, forestry and municipal wastes) and targets of ensuring $200 \mathrm{MW}$ by 2020 and $400 \mathrm{MW}$ by 2030 were defined for developing the potential of bioelectricity in Morocco. Geothermal energy is still not used for electricity production due to economic and technical feasibility, but a study [22] in north-eastern Morocco has estimated the potential of geothermal electricity at 5 MWe. Simultaneously, the country set the target of saving up to $12 \%$ of consumed energy by 2020 (compared to 2011), and between $25 \%$ and $30 \%$ by 2030 . These targets were introduced under the National Programme for Energy Efficiency (NPEE) in 2011. This programme defined five principal sectors for enhancing of energy efficiency measures including households, industry, agriculture, transport and tertiary (hospitals, hotels, restaurants, schools and other public services).

\section{Materials and methods}

In order to evaluate the potential of carbon dioxide mitigation in the Moroccan electricity sector, we will build a System Dynamics (SD) model depicting the current structure of this 
sector. SD is a modelling and simulation approach for analyzing complex systems by studying the interactions of their elements along with their feedbacks and delays. The main objective is to understand the evolution of the system and its causes [23].

The reason behind this selection lies in:

- The high level of technical details in modelling the national electricity market;

- The flexibility of this market due to different parameters and conditions; and

- The wide and successful use of this approach for addressing similar issues worldwide [24 and 25].

The data for conducting this study were collected from different sources including: governmental electronic publications, international studies and reports, and journal articles [26-29].

\section{Results and discussion}

\subsection{Model scenarios}

The time span of our model is defined over the period 2015-2030. This choice enables the validation of the model by comparing its outcomes with previous governmental studies and institutional reports for the same period. Moreover, this period covers the overall term of the NES.

Three scenarios were selected for simulating the model including:

- The Base scenario: this scenario follows the current trends of the Moroccan electricity sector. It suggests an annual electricity demand growth rate of $7.5 \%$. Additionally, the energy mix will keep being dominated by fossil fuels (66\%) and a limited share of renewables $(34 \%)$. The role of this scenario is to serve as a reference for comparisons between other scenarios and their benefits for the overall electricity system.

- The Renewable Energy (RE) scenario: this scenario reflects the targets of the NES. Total installed capacity of renewables is expected to reach $52 \%$ by 2030 and the annual electricity demand growth rate is fixed at $7 \%$.

- The Renewable Energy (RE) and Energy Efficiency (EE) scenario: this scenario is considered as an ideal yet a promising pathway for the future of the Moroccan electricity sector. Within the RE+EE scenario, the total installed capacity of renewables is expected to reach $59 \%$ by 2030 and the annual electricity demand growth rate has decreased to $6.5 \%$ due to the enhancement of energy efficiency measures.

\subsection{Electricity supply and demand}

Figure 1 and Figure 2 show the development of renewable and fossil installed capacity between 2015 and 2030. The initial installed capacity of renewables in 2015 was 2,822 MW in the three pre-defined scenarios, while the initial installed capacity of fossil fuels in 2015 was 5,478 MW in the same scenarios. According to the base scenario, the renewable installed capacity will reach $6,927 \mathrm{MW}$ by 2030 compared to $14,222 \mathrm{MW}$ in the RE scenario and 15,622 MW in the RE+EE scenario. On the other hand, the fossil installed capacity amounts to $16,518 \mathrm{MW}$ by 2030 in the base scenario compared to $10,528 \mathrm{MW}$ in the RE scenario and 9,728 $\mathrm{MW}$ in the RE+EE scenario. This enormous increase in renewable installed capacity is attributed mainly to the exploitation of solar $(5,416 \mathrm{MW}$ in the RE scenario and 5,916 MW in the RE+EE scenario by 2030) and wind (5,330 MW in the RE scenario and 5,830 MW in the RE+EE scenario by 2030) energies, while hydropower (3,076 MW in the RE scenario and 3,176 MW in the RE+EE scenario by 2030) and biomass (400 MW in the RE scenario and $700 \mathrm{MW}$ in the RE+EE scenario by 
2030) contribution will be limited following their available potential in the country. Oil is expected to decrease to reach $1175 \mathrm{MW}$ in the RE scenario and $1075 \mathrm{MW}$ in the RE+EE scenario compared to $6275 \mathrm{MW}$ in the base scenario. This decrease in mainly attributed to the increasing prices of oil imports compared with coal and natural gas. Coal installed capacity is expected to increase in the three scenarios reaching $7748 \mathrm{MW}$ in the base scenario, $4948 \mathrm{MW}$ in the RE scenario, and $4448 \mathrm{MW}$ in the RE+EE scenario. Natural gas will experience the highest increase due to its lower carbon footprint and adaptability with CHP plants. The installed capacity of natural gas will reach $2495 \mathrm{MW}$ in the base scenario, $6080 \mathrm{MW}$ in the RE scenario, and $5580 \mathrm{MW}$ in the RE+EE scenario.

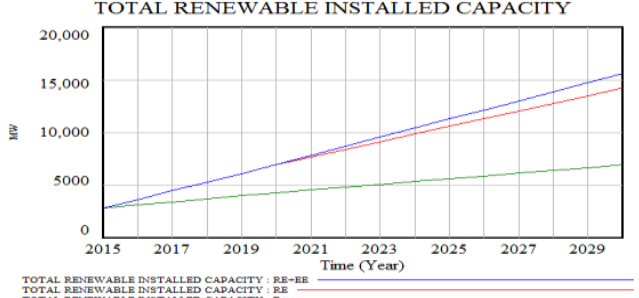

Fig.1. The total renewable installed capacity in Morocco up to 2030.

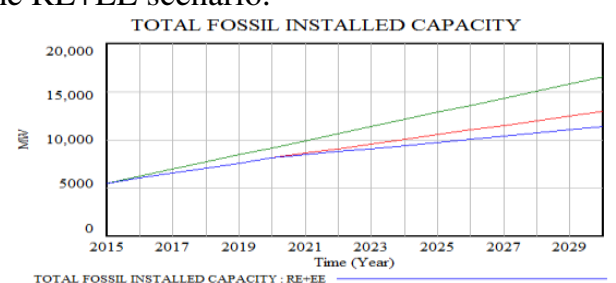

TOTAL FOSSIL INSTALLED CAPACITY : RE+EE
TOTAL FOSII NSTALLED CAPACIY : RE
TOTAL FOSSII NNSTALLED CAPACITY : Base

Fig.2. The total fossil installed capacity in

Morocco up to 2030.

Electricity production from renewables and fossil fuels is following the same patterns as it is shown in Figure 3 and Figure 4. The initial renewable electricity generation in 2015 was $6095.92 \mathrm{GWh}$ in the three scenarios, while the initial fossil electricity generation in 2015 was $22098.3 \mathrm{GWh}$ in the same scenarios. It is noteworthy to mention that fossil fuels are still efficient in terms of energy output compared to renewables. However, wind and hydroelectric plants are witnessing progressive advances to close the gap between renewables and fossil technologies. According to the base scenario, renewable electricity generation will reach $14962.3 \mathrm{GWh}$ by 2030 compared to $30719.5 \mathrm{GWh}$ in the RE scenario and $33743.5 \mathrm{GWh}$ in the RE+EE scenario. On the other hand, fossil generated electricity will amount to $66633.6 \mathrm{GWh}$ by 2030 in the base scenario compared to $52252.4 \mathrm{GWh}$ in the RE scenario and $45798 \mathrm{GWh}$ in the RE+EE scenario.

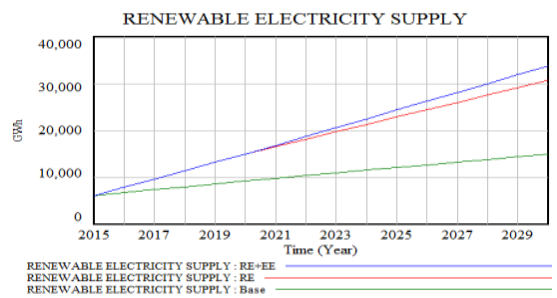

Fig.3. The renewable electricity supply in

Morocco up to 2030.

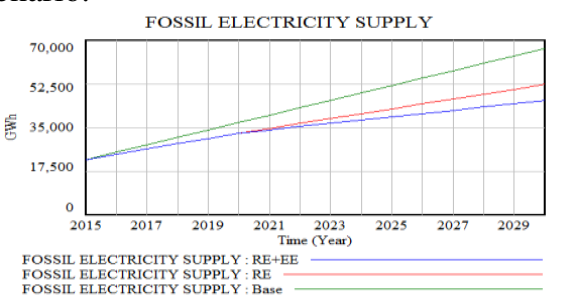

Fig.4. The fossil electricity supply in

Morocco up to 2030.

Electricity demand will range between $97652.8 \mathrm{GWh}$ in the RE+EE scenario, 104,760 GWh in the RE scenario and $112,349 \mathrm{GWh}$ in the base scenario (see Figure 5). This suggests a gap of $30,754 \mathrm{GWh}$ in the base scenario, $18755.1 \mathrm{GWh}$ in the RE scenario, and 18111.3 GWh in the RE+EE scenario. It must be highlighted that advances in renewable energy outcomes can close the supply/demand gap and even led the country to export the surplus of green energy using its connections with Spain and Algeria. 


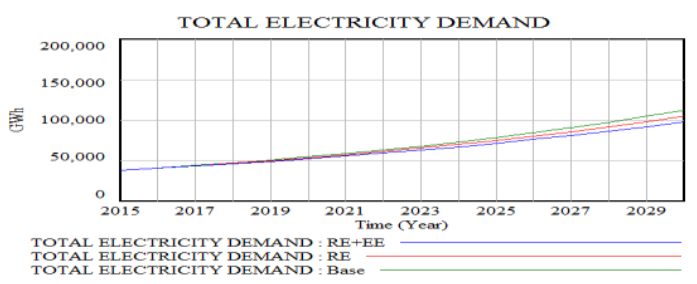

Fig.5. The total electricity demand in Morocco up to 2030.

\subsection{CO2 emissions in the Moroccan electricity sector}

The carbon dioxide emissions of the Moroccan electricity sector were calculated for the three scenarios by including direct and indirect $\mathrm{CO} 2$ emissions. The direct emissions enclose the emissions from the combustion/gasification process while the indirect emissions are linked to the fuel supply chain and the plant construction [37]. Depending on fuel type and technology, direct emissions could vary between $850 \mathrm{~kg} \mathrm{CO} 2 / \mathrm{MWh}$ in case of Circulating Fluidised Bed Combustion (CFBC) of coal to $60 \mathrm{~kg} \mathrm{CO} / \mathrm{MWh}$ in case of Combined Cycle Gas Turbine with Carbon Capture and Storage (CCS). Accordingly, indirect emissions are ranging between $125 \mathrm{~kg} \mathrm{CO} 2 / \mathrm{MWh}$ in case of Integrated Gasification Combined Cycle (IGCC) or Pulverised Coal Combustion (PCC) to $70 \mathrm{~kg}$ $\mathrm{CO} 2 / \mathrm{MWh}$ in case of Combined Cycle Gas Turbine with CCS. Regarding renewables, only biomass (6 kg CO2/MWh for solid biomass and $5 \mathrm{~kg} \mathrm{CO} 2 / \mathrm{MWh}$ for biogas) and solar (120 $\mathrm{kg} \mathrm{CO} 2 / \mathrm{MWh}$ for Concentrating Solar Power (CSP) in case of using natural gas for backup heat production) can emit direct $\mathrm{CO} 2$ emissions. Indirect emissions range from $6 \mathrm{~kg}$ $\mathrm{CO} 2 / \mathrm{MWh}$ in case of hydroelectric plants (either small or large) to $45 \mathrm{~kg} \mathrm{CO} 2 / \mathrm{MWh}$ in case of photovoltaic plants.

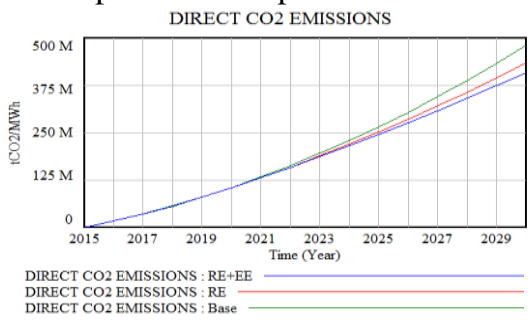

Fig.6. The cumulative direct $\mathrm{CO}_{2}$ emissions of the Moroccan electricity sector up between

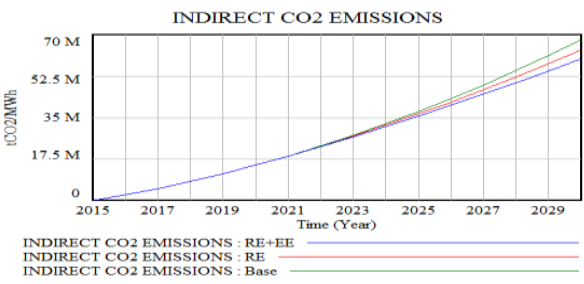

Fig.7. The cumulative indirect $\mathrm{CO}_{2}$ emissions of the Moroccan electricity sector between 2015 and 2030 .

2015 and 2030.

According to Figure 6, the cumulative direct $\mathrm{CO} 2$ emissions of the Moroccan electricity sector over the period 2015 - 2030 are estimated at $480.37 \mathrm{MtCO} 2$ in the base scenario compared to $433.75 \mathrm{MtCO} 2$ in the RE scenario and 406.69 MtCO2 in the RE+EE scenario. This implies avoiding 10\% (in case of the RE scenario) and $15 \%$ (in case of the RE+EE scenario) of direct carbon dioxide emissions of the Moroccan electricity sector if appropriate measures were taken to further deploy renewable energies and enhance energy efficiency measures.

The cumulative indirect $\mathrm{CO} 2$ emissions of the Moroccan electricity sector over the same period re illustrated in Figure 7. Since most of these emissions are emitted from fossil fuels, the same patterns of behavior can be seen in this Figure. The cumulative indirect emissions in the base scenario amounts to $67.81 \mathrm{MtCO} 2$ compared to $63.65 \mathrm{MtCO} 2$ in the $\mathrm{RE}$ 
scenario and $59.78 \mathrm{MtCO} 2$ in the RE+EE scenario. Almost $6.13 \%$ (in case of the RE scenario and $11.67 \%$ (in case of the RE+EE scenario) of indirect carbon dioxide emissions could be avoided by achieving the pre-mentioned targets. The decrease in the share of avoided emissions reflects the indirect emissions of constructing and fueling some renewable energy plants. Overall, the total avoided $\mathrm{CO} 2$ emissions in the Moroccan electricity sector can amount to $9.28 \%$ (in case of the RE scenario) and $14.9 \%$ (in case of the RE+EE scenario).

It is noteworthy to mention that the results of this study seem to be in line with previous studies regarding the potential of carbon dioxide mitigation in the Moroccan energy sector.

\subsection{Challenges and recommendations}

It is obvious that the fulfillment of the mentioned plans will change the electricity sector completely in Morocco during the upcoming years and placing the country as the forefront of clean energy users worldwide. However, many challenges and barriers are still hindering the smooth deployment of these projects and must be addressed holistically by different stakeholders. The aim is to achieve the governmental targets and increase the attractiveness of this potential on a global scale. To this end, major challenges are categorized into five areas: political, technical, economic, social, and environmental barriers. The main obstacles of each category are provided below (based mainly on the guidelines of IEA [26]) along with key recommendations to alleviate their impacts on the implementation of the NES.

\subsubsection{Political challenges and recommendations}

This category encloses institutional and regulatory aspects of the electricity sector in Morocco. Major obstacles include the lack of an integrated approach for alternative energy deployment in the country. Moreover, the Moroccan electricity sector is still highly monopolized by ONEE although to a less extent than before. This situation is not suitable for increasing the share and the competitiveness of alternatives compared to conventional technologies. Finally, the lack of information and data is still hindering the access of different social segments and utilities to this green knowledge, which is urgently required for answering different issues of renewables in Morocco. To overcome these barriers, an inclusive approach - favoring partnership and cooperation - must be implemented in order to allow different stakeholders to take part in developing national policies for renewable and alternative energy. Furthermore, encouraging domestic and industrial IPPs to integrate the Moroccan electricity sector is capable of increasing the installed capacity (along with electricity generation) of renewables and security of supply (in contrast to monopolistic power generation). Finally, collecting and providing public access to relevant data and information on renewables will most likely accelerate the deployment of renewable and alternative energy in Morocco.

\subsubsection{Technical challenges and recommendations}

These obstacles relate mainly to the intermittent nature of renewables. This can affect energy security and widen the gap between supply and demand, which led to increasing energy imports. Moreover, the field of renewable energy is not mature yet in Morocco, and there is an urgent need for technology expertise and qualified personnel on a local scale. In addition to the importance of developing other renewable technologies (namely biomass and geothermal), a need for a flexible regulating energy is urgently required in order to balance supply and demand, and decrease energy imports. CHP stands as a suitable technology for Morocco due to its overall efficiency, which is high compared to separate heat and power generation. Moreover, CHP technologies are relatively cleaner in terms of $\mathrm{CO} 2$ emissions. It is noteworthy to mention the importance of increasing the installed 
capacity of renewables in different regions of Morocco in order to minimize the impact of their intermittency on security of supply. Simultaneously, energy storage stands as an important strategy for reducing the sector failures due to instability of renewables.

Additionally, promoting R\&D projects can fill the gap in terms of local human potential in this area. These projects can be conducted through partnerships between Universities and power industries. In addition, technology transfer can play a major role within this scope, and Morocco could potentially benefit from successful experience of some leading nations in this domain.

\subsubsection{Economic challenges and recommendations}

These barriers are of great importance and they represent the main driving force behind the reluctant investment of capitals in the field of renewables. In fact, despite the advantages of renewables and their great potential in Morocco, the state is still facing complicated issues for attracting local and foreign investments in the area. This situation is due to the intermittent nature of renewables, their high construction and O\&M (Operation and Maintenance) costs, their long span of time concerning return on investment, and the lack of financial aids from the Moroccan government to develop renewable projects. Morocco can use financial savings from cutting fuel subsidies to support local and foreign IPPs and $\mathrm{R} \& \mathrm{D}$ activities in the field of renewables. In addition, developing local businesses for installing and operating renewable projects can decrease their global costs and thus provide renewable electricity at an affordable price. Finally, different financial schemes must be implemented by the government in order to support the deployment of renewables. This include feed-in tariff for IPPs and taxes for conventional energy.

\subsubsection{Social challenges and recommendations}

The success of renewable energy deployment in Morocco relies among other reasons on social awareness and acceptance of these technologies in the energy mix. Unfortunately, the lack of educational programs on renewable energy is responsible for social lack of appreciation towards renewables and their enormous potential and opportunities. Moreover, the lack of best practices for energy efficiency is highly witnessed among different social layers in Morocco. Raising the understanding of renewables and their potential can be ensured through strong governmental policies including educational programs, informational campaigns, and engagement of different social segments in the process of sustainable development based on participative democracy.

\subsubsection{Environmental challenges and recommendations}

Although renewables present the ideal option for Morocco in order to achieve a sustainable development of the electricity sector, they also have some environmental impacts mainly in the area of hydropower and biomass. Moreover, the prospective reliance on nuclear energy can generate adverse effects on the ecosystem if safety measures were not taken. In fact, hydropower (particularly run-of-the-river technologies) is always linked to a massive disruption of the ecosystem resulting from the construction and the operation of hydropower plants near to some sensitive areas. Additionally, the intensive use of biomass (namely food crops) for generating electricity can lead to major impacts on the Moroccan agriculture and sylviculture sectors. Consequently, the environmental aspect of renewable energy has to be placed at the core of the NES in addition to the national plans for mitigating CO2 emissions. Major measures to reduce the ecological footprint of renewable plants (mainly hydropower and biomass) include afforestation, micro- and WWTP hydropower palnts, and R\&D activities. 


\section{Conclusions}

The present study shows that RE and EE measures are the main strategies to answer the growing electricity demand in Morocco and mitigate $\mathrm{CO} 2$ emissions. In fact, RE plants have a potential of ensuring up to $36 \%$ of total electricity generation by 2030 if the targets of the NES were achieved. Moreover, an additional $6 \%$ of total electricity generation can be gained from further investments and implementation of EE measures. Consequently, the cumulative potential of carbon dioxide mitigation over the period $2015-2030$ could reach up to $50.78 \mathrm{MtCO} 2$ in the case of RE scenario and $81.7 \mathrm{MtCO} 2$ in the case of RE+EE scenario. This study can be conducted in other countries or regions having similar energy situation as Morocco. Moreover, the outcomes of this study can be enlarged by studying the mitigation potential of the Moroccan heat sector and also of other sectors like transportation, industry and construction.

\section{Acknowledgments}

- This research was supported by the National Center of Scientific and Technical Research (CNRST) in Morocco through the scholarship of excellence Number 22UAE2016.

\section{References}

1.IPCC, Climate change 2007 synthesis rerpot (2007).

2.Union of concerned scientists, Why does $\mathrm{CO}_{2}$ gets most of the attention when there are so many other heat-trapping gases (greenhouse gases)? (available online) [accessed on 17 May 2017].

3. Vaughan, A.,Global carbon dioxide levels break 400ppm milestone, The Guardian, (May 2015).

4.Amos J., Carbon dioxide passes symbolic mark, BBC, (May 2013).

5.IPCC, Climate change 2014: Mitigation of climate change, chapter 7: energy systems, Cambridge University press, (2014)

6. IEA, Energy technology perspectives - part 3: fossil fuels and CCS, (2012).

7. IEA, Cogeneration and renewables: solutions for a low-carbon energy future, (2011).

8. HCP, RGPH 2014, (2015).

9. Altmanm K. A bright future for Morocco, (2012) 33-35.

10. HCP, Prospective Maroc 2030 - Energie 2030 : prospective énergétique du Maroc Enjeux et défis, (2011).

11. ONEE, Le marché de l'énergie électrique au Maroc, (2015).

12. ONEE, Rapport d'activités, (2015).

13. IEA, statistics for Morocco (available online) [accessed on 12 April 2017].

14. Ministry Delegate of the Minister of Energy, Mines, Water and Environment, in charge of Environment, Moroccan Climate Change Policy (MCCP), (March 2014).

15. Tramblay Y., Badi W., Driouech F., El Adlouni S., Neppel L., Servat E., Climate change impacts on extreme precipitation in Morocco, Gloval and Planetary Change 8283 (2012) 104-114.

16. Simonneaux V., Cheggour A., Deschamps C., Mouillot F., Cerdan O., Le Bissonnais Y., Land use and climate change effects on soil erosion in a semi-arid mountainous watershed (High Atlas, Morocco), Journal of Arid Environments 122 (2015) 64-75.

17. Seif-Ennasr M., Zaaboul R., Hirich A., Caroletti G., Bouchaou L., El Morjani Z., Beraaouz E., McDonnell R., Choukr-Allah R., Climate change and adaptive water management measures in Chtouka Ait Baha region (Morocco), Science of the Total Environment 573 (2016) 862-875 
18. GIZ, Establishment of a national competence centre for climate change mitigation and adaptation in Morocco (4C Maroc) (available online) [accessed on 19 April 2017].

19. 4C Maroc, 3ème Communication Nationale du Maroc à la Convention Cadre des Nations Unies sur le Changement Climatique : Des mesures d'atténuation proposées à l'horizon 2040, (February 2016).

20. SIEM, Invest in renewable energies in Morocco (available online) [accessed on 25 April 2017].

21. Adriani B, Lignières $P$, Barges M, Bennis A, Mokhtari G, Lighting up the kingdom of Morocco: energy strategy and recent developments in power projects, (2013).

22. Zarhloule Y. Geothermal potentialities of Morocco, online (https://www.fsb.unizg.hr) [accessed 7 March 2017]

23. Forrester J.W., Industrial Dynamics, Pegasus Communications, (1961).

24. Saysel A., Hekimoglu M., Exploring the options for carbon dioxide mitigation in Turkish electric power industry: System dynamics approach, Energy policy 60 (2013) 675-686.

25. Robalino-Lopez A., Mena-Nieto A., Garcia-Ramos J.E.? System dynamics modeling for renewable energy and $\mathrm{CO}_{2}$ emissions: A case study of Ecuador, Energy for Sustainable development 20 (2014) 11-20.

26. IEA, Morocco 2014 - energy policies beyond IEA countries, (2014).

27. The 1 Gigaton coalition, Renewable energy and energy efficiency in developing countries: contributions to reducing global emissions, (2016).

28. IEA, Clean energy technology assessment methodology pilot study: Morocco, (2016).

29. Commission of the European Communities, Energy sources, production costs and performance of technologies for power generation, heating and transport, (2008). 